\title{
Occurrences Rate of Type II and III Solar Radio Bursts at Low Frequency Radio Region $45-870 \mathrm{MHz}$
}

\author{
Z. S. Hamidi ${ }^{1, *}$, N. N. M. Shariff ${ }^{2}$, C. Monstein ${ }^{3}$ \\ ${ }^{1}$ School of Physics and Material Sciences, Faculty of Sciences, MARA University of Technology, \\ 40450, Shah Alam, Selangor, Malaysia \\ ${ }^{2}$ Academy of Contemporary Islamic Studies (ACIS), MARA University of Technology, \\ 40450, Shah Alam, Selangor, Malaysia \\ ${ }^{3}$ Institute of Astronomy, Wolfgang-Pauli-Strasse 27, Building HIT, \\ Floor J, CH-8093 Zurich, Switzerland \\ *E-mail address: zetysh@salam.uitm.edu.my
}

\begin{abstract}
Observations of type II and III solar bursts indicate that while type III bursts may appear at any altitude, from the very low corona into interplanetary space, type II solar bursts do not act the same way. This work focuses on recent observations in the radio region on the low frequency region from $45 \mathrm{MHz}$ to $870 \mathrm{MHz}$. Our analysis employed the accuracy of the daily solar burst measurements of eCALLISTO network. It was found that solar burst type II explode quite minimum with 1-2 events from 2006 - 2010. However, the data 2011 for solar burst type II increases drastically with 16 events has been recorded. The occurrences of Coronal Mass Ejections (CMEs) events are also increasing up to four times in 2011. Most of the both events can be observed in the range of $150 \mathrm{MHz}$ till $500 \mathrm{MHz}$. Overall, we can say that the range of photon energy for solar burst type III is between $7.737 \times 10^{-7} \mathrm{eV}$ to $1.569 \times 10^{-6} \mathrm{eV}$. In the case of solar burst type II, the distribution of energy is much smaller with $1.596 \times 10^{-6} \mathrm{eV}$ to $6.906 \times 10^{-6} \mathrm{eV}$. Detailed investigation of solar burst will concern the 2011 data seem to show a significant trend for both types. We showed that the increasing of both solar burst events via years implies directing an increasing of solar activities including sunspot number, solar flare and Coronal Mass Ejections (CMEs) events. It is expected that both types will increase gradually in the beginning of 2014.
\end{abstract}

Keywords: CALLISTO; low frequency; solar burst: type II, type III; solar flare; Coronal Mass Ejections (CMEs)

\section{INTRODUCTION}

The energy of the Sun in a wide range of the energy spectrum covers from long radio waves $(300 \mathrm{~m})$ to $X$-rays $(0.1 \mathrm{~nm})$ [1,2]. It is not a surprise that almost all solar activity phenomena are associated in this way or another with the 11 and 22-years sunspot cycle $[3,4]$.

In a wide region, solar radio emission has become increasingly interested in attempts to understand the Sun activities during maximum and minimum cycle [5]. It is well-known that the radio emission is generated at the local plasma frequency and/or its second harmonic $[6,7]$. It is produced by either energetic electrons accelerated at the shock front or plasma turbulence excited by the shock [8]. There are two solar burst type that associated with CMEs 
event, type II and III respectively [8,9]. Normally, type III can be observed before the explosion of CMEs. It is believed that type III bursts are caused by mildly relativistic electrons (10-100 keV) that are produced in impulsive solar flares, because bursts commonly occur in groups of 10 or more, with a separation of seconds [10,11]. Meanwhile, solar type II radio bursts are defined as slow drifting features in radio spectrogram data [12]. Thought to be caused by plasma radiation from shock-accelerated electrons, the burst is often observed as two bands of emission in the local plasma frequency $\left(v_{p}\right)$ and its harmonic [13]. The most direct diagnostic of shock waves in the solar corona is metric type II bursts [14]. The dynamic spectra of type II radio bursts appear as slowly drifting bands, from high to low frequencies. Most type II bursts appear typically below $150 \mathrm{MHz}$ [15], but occasionally the starting frequency may be as high as $500 \mathrm{MHz}$ [16].

Detailed discussions of the properties of type II bursts are given by $[17,18,19,20]$. Observations of low frequency solar type III radio bursts associated with the ejection of plasma oscillations localized disturbance is due to excited in the plasma frequency incoherent radiations plays a dominant role at a meter and decimeter wavelengths which may be associated with the flare primary energy-releasing sites [21,22]. The frequency drift rates of type II bursts are on the order of $0.3 \mathrm{MHz} / \mathrm{s}$ and are found to increase with increasing starting frequency in the meter wavelength range [23]. Observations of type II and III bursts indicate that while type III bursts may appear at any altitude, from the very low corona (corresponding to gigahertz frequencies) to interplanetary space (corresponding to kilohertz frequencies), type II bursts do not behave the same way: the reported highest frequencies of the fundamental components of type II bursts usually do not exceed a few hundred $\mathrm{MHz}$ [24-28]. It has been known for decades that about $50 \%$ of type II bursts are preceded by a group of type III bursts by several minutes [29]. Recently, it has been shown that the overall frequency envelope of the precursor type III bursts.

There a several mechanisms have been discussed in the literature, most of which require some form of magnetic reconnection during and after the eruption [30]. The eruption mechanism of Coronal Mass Ejections (CMEs) is currently an extremely active area of solar activities. CME-driven shock plays a much more important role in exciting the type II radio bursts than any flare-related blast wave. However, how far type III formed a type II is still unpredictable. The mechanism of generation of type II bursts is still a matter of ongoing study. Therefore, our study focused on Coronal Mass ejections (CMEs), the most spectacular eruptions in the solar atmosphere and has been recognized as primary drivers of interplanetary disturbances and can be detected by type II burst. Here, we analyzed statistically solar burst obtained from e-CALLISTO network starting from January 2006 to December 2011 [31]. The correlations between total duration, peak, flux and total energy of extended decimeter of solar burst types III and II bursts will be studied [11,32].

\section{THEORETICAL REVIEW}

Although solar flare and Coronal Mass Ejections (CMEs) are difference event, most of the explosion of CMEs occurs during a high energy of solar flares [33]. Current theories of the origin of solar radio bursts suggest that fast drift (Type III) bursts may be generated by the emission of solar particles with velocities approaching those of cosmic rays. Type III burst groups can be divided into two classes, one with weak polarization and wet periods over a wide range up to 6 seconds, the other with strong polarization and short periods less than two 2 seconds and smaller size compact sources. On the other hand, an alternative exciter of the type II radio burst is the so-called blast wave, which is believed to originate in proximity to the solar flare where based on the idea that the flare takes place explosively, like a bomb 
blowing out the nearby material in every direction [34]. Development of a burst is often accompanied by a richness which may take the form of multiple independent drifting bands or other forms of fine structure. The main band is split into two sub-bands because of the effect of magnetic splitting, analogous to the Zeeman effect $[13,35,36]$. Type II radio bursts normally appearing in the metric $(\mathrm{m})$ and decameter-to-hectometer (DH) wavelength ranges $[37,38]$. Various studies showed that type II solar radio burst associated with X-ray flares and Coronal Mass Ejections (CMEs) [1,9].

\section{STATISTICAL PROPERTIES}

This work focuses on recent observations in the radio region at low frequency from 45 $\mathrm{MHz}$ to $870 \mathrm{MHz}[39,40]$. The CALLISTO (Compound Astronomical Low-cost Lowfrequency Instrument for Spectroscopy in Transportable Observatory) spectrometers, designed and built by electronics engineer Christian Monstein was particularly useful for studying the large explosions in the Sun's atmosphere known as solar flares and Coronal Mass Ejections (CMEs) [41,42]. Malaysia also started joining this research since 20th February 2012 and routinely monitor 12 hours per day at National Space Centre, Selangor [43,44,45]. This site has been chosen as a main site for radio astronomy because it is less in term of population density [46,47]. Preliminary analysis of determining the Radio Frequency Interference (RFI) at National Space Centre [46,48,49,50,51,52]. Construction and modification of the Log Periodic Dipole Antenna has been done at the first stage of the project $[50,53,54,55]$. So far we have two different sizes of antenna (i) 5.5 meters and (ii) 3.1 meters $[56,57]$. Our analysis employed the accuracy of the daily solar burst measurements of e-CALLISTO network [58,59].

Table 1. The statistic of solar bursts type II and III from 2006-2011.

\begin{tabular}{|c|c|c|}
\hline Year & Type II & Type III \\
\hline 2006 & 2 & 15 \\
\hline 2007 & 2 & 19 \\
\hline 2008 & 1 & 10 \\
\hline 2009 & 2 & 31 \\
\hline 2010 & 2 & 1 \\
\hline 2011 & 16 & 200 \\
\hline
\end{tabular}

Normally, solar radio burst is used as 1) the basic indicator of solar activity; and 2) to determine the level or radiation being received from the Sun [44,60]. A detailed compilation of solar burst has been compiled and updated by Institute of Astrophysics, ETH, Switzerland. Here we highlight the distribution of type II and III burst started from 2006 till 2011 $[41,61,62]$.

Available results in Table 1 of the observation showed that there is a small detection within five years beginning from 2006-2010. It should be noted that there is only one detection solar burst type III in 2010. However, the pattern drastically increases in 2011 . Here are many factors that affected by the results. First, this is due to the trend of solar activities 
that increases during that time.Second factor is due to an additional sites that also used a same system make the possibilities to detect and monitor the Sun with longer of period of observation.

Table 2. Physical Properties of solar radio burst type II and III from 2006 - 2011.

\begin{tabular}{|c|c|c|c|c|}
\hline Type & $\begin{array}{c}\text { Maximum } \\
\text { rate per } \\
\text { month }\end{array}$ & $\begin{array}{c}\text { Burst } \\
\text { duration } \\
\text { (average) } \\
\text { per event }\end{array}$ & $\begin{array}{c}\text { Average } \\
\text { low } \\
\text { frequency } \\
\text { per event } \\
\text { (MHz) }\end{array}$ & $\begin{array}{c}\text { Average } \\
\text { high } \\
\text { frequency } \\
\text { per event } \\
\text { (MHz) }\end{array}$ \\
\hline II & 3 & $\begin{array}{c}5 \text { minutes } 5 \\
\text { second }\end{array}$ & 167 & 386 \\
\hline III & 17 & $\begin{array}{c}1 \text { hour } 8 \\
\text { minutes } \\
\text { and 3 } \\
\text { seconds }\end{array}$ & 187 & 449 \\
\hline
\end{tabular}

Table 2 shows the physical properties of both solar bursts. It is found that type III has a wide range of frequency compare with type II. However, the average of type III to form type II quite long. It will take about an hour to form type II burst. Moreover, most of type III is in a group and there will be a stronger signal of this burst before Coronal Mass Ejections (CMEs) exploded.

\section{RESULTS AND DISCUSSIONS}

It was observed that type III had been found to be moderately elliptically polarized. The degree of polarization can achieve up to $70 \%$ with a certain preference for about 30 to $60 \%$. Solar burst type III always associated with solar flare phenomena. There is evidence showed that type III electrons propagate in dense coronal streamers, and that frequently observed micro bursts (presumably of type III) at meter-decameter wavelengths are due to plasma radiation. The analysis method is based on the results of recording of the detection of the number of both type within six years. It cannot be denied that type III is the dominant solar burst. If we compare with other types, type II is the most unpredictable burst. Like the slowdrift bursts, this type also comparatively rare. The rate of occurrence is also small.

It was found that solar burst type II explode quite minimum with 1-2 events from 20062010. Again, the data 2011 for solar burst type II increases drastically with 16 events has been recorded. The number of events also multiplied four times in 2011.We examine the distribution of this bright and polarized structure burst for each month and we found that the maximum event was recorded in February. The range of frequency of this burst is from 167 $\mathrm{MHz}$ till $386 \mathrm{MHz}$ with duration less than 6 minutes. This observation proved that a system with high resolution is needed to detect the burst. Though type II is well known caused by magneto hydrodynamic shock waves, one should concerns solar flare and Coronal Mass Ejections (CMEs) formation as a part of solar activities. 
During the eruption process a whole host of radio bursts caused by nonthermal electrons accelerated that is associated with Coronal Mass Ejections (CMEs). This disturbance originating at the Sun can lead to many hazardous effects in the Geospace environment. In contrast, the minimum detection of solar burst type II with once event occurred in 2008. It showed the correlation with the solar activities during this year.

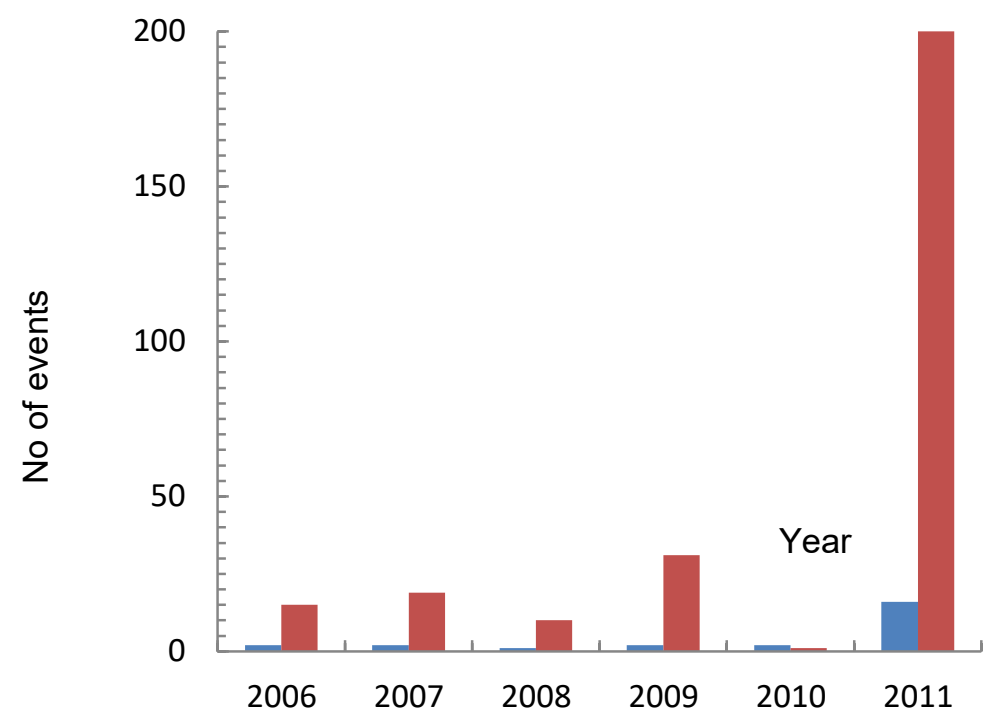

Figure 1. Distribution of type II and III burst within six years

The results largely confirmed that this type is the main type that formed the maximum events until now. It is dominating the records of solar activity in the meter-wavelength spectrum. Normally, when a type III sources are ejected outwards from near the limb of the Sun, the radio source should appear beyond the limb and its angular displacement from the limb should increase as the frequency decreases. The drift of solar burst type III is believed due to ionized matter streaming up through solar atmosphere, exciting plasma oscillation at both fundamental and harmonic frequencies. Single burst are not common except during quiet times at low frequencies, where the radiation lasts for some ten minutes. It is generally assumed that complex events can be described as a combination of individual bursts, although isolated single burst occurs rarely. However, it may be that in such complex events other phenomena such as type II and IV radiation are involved. We can say that this type is rich in variety. One interesting fact is that at one extreme are the uncomplicated bursts with a sharply defined leading edge, narrow bandwidth and a short duration which increases with decreasing frequency. Recent high resolutions $\mathrm{H} \alpha$ brightening which is also associated with $\mathrm{X}$-rays and microwave bursts. Overall, there are 276 events solar burst type III has been recorded within 6 years. A majority occurred in 2011 with 200 events. This type is very synonymous with the solar flare phenomenon. The only one CALLISTO network could detect this type in 2010 is on $12^{\text {th }}$ February 2010 within 3 hours and 50 minutes. This burst is due to Sunspot 1046 is crackling with M-class solar flares. If we plot by month, this type quite passive in the middle of each year. Moreover, most of this type occurred as a single type in 2011 with the range of frequency from $187 \mathrm{MHz}$ till $449 \mathrm{MHz}$. This type seldom be accompanied by a second harmonic specifically occurred during the solar flare phenomenon. 


\section{CONCLUDING REMARKS}

Detailed investigation of solar burst will concern the 2011 data seem to show a significant trend for both types. From the analysis, we can conclude that solar burst type II will form after a consistent one hour duration of solar burst type III. Most of the both events can be observed in the range of $150 \mathrm{MHz}$ till $500 \mathrm{MHz}$. Overall, we can say that the range of photon energy for solar burst type III is between $7.737 \times 10^{-7}$ to $1.569 \times 10^{-6} \mathrm{eV}$. In the case of solar burst type II, the distribution of energy is much smaller with $1.596 \times 10^{-6} \mathrm{eV}$ to $6.906 \mathrm{x}$ $10^{-6} \mathrm{eV}$. The most comprehensive sampling of solar burst has been analyzed using CALLISTO network data from different sites. E-CALLISTO research was launched on 2006 January and is still operating until now. Solar radio bursts potentially provides possibilities of important phenomena in solar physics. It is an ideal indicator on investigating acceleration processes which are responsible for higher excited velocities We showed that the increasing of both solar burst events via years implies directly an increasing of solar activities including sunspot number, solar flares and Coronal Mass Ejections events. Although the study has been conducted more that fifty years, the dynamism and the trend of the solar burst is different for each solar cycle. This study becomes more relevant seems modern society now depends with satellite technologies that might affected by solar phenomena. Our next task is to consider others parameters such as the number of sunspots, sunspot area, radio flux distribution and other factors in order to understand the trend of both solar burst during the solar maximum cycle. It is expected that both types will increase drastically in the beginning of 2014 .

\section{Acknowledgement}

We are grateful to the LASCO,SDO/AIA, NOAA and SWPC make their data available online. This work was partially supported by the FRGS (600 RMI/FRGS 5/3 2012) UiTM grants. Special thanks to the National Space Agency and the National Space Centre for giving us a site to set up this project and support this project. Solar burst monitoring is a project of cooperation between the Institute of Astronomy, ETH Zurich, and FHNW Windisch, Switzerland, MARA University of Technology and University of Malaya. This paper also used NOAA Space Weather Prediction Centre (SWPC) for the sunspot, radio flux and solar flare data for comparison purpose. The research has made use of the National Space Centre Facility and a part of an initiative of the International Space Weather Initiative (ISWI) program.

\section{Biography}

Dr Zety Sharizat Hamidi is currently a senior lecturer and focused in Solar Astrophysics research specifically in radio astrophysics at the School of Physics and Material Sciences, Faculty of Sciences, MARA University of Technology, 40450, Shah Alam, Selangor, Malaysia. Involve a project under the International Space Weather Initiative (ISWI).

Dr Nur Nafhatun Md Shariff is a senior lecturer at Academy of Contemporary Islamic Studies (ACIS), MARA University of Technology, 40450, Shah Alam, Selangor, MalaysiaHer current research is more on sustainability; environmental aspect. She is looking forward for cross-field research, i.e. solar astrophysics, light pollution measurement (mapping) and religious studies.

C. Monstein is a senior Engineer at Institute of Astronomy, Wolfgang-Pauli-Strasse 27, Building HIT, Floor J, CH-8093 Zurich, Switzerland and one of the researchers who initiated the CALLISTO system around the world. 


\section{References}

[1] Z. Hamidi, N. Shariff, C. Monstein, W.W. Zulkifli, M. Ibrahim, N. Arifin, N. Amran, International Letters of Chemistry, Physics and Astronomy 8 (2013) 13-19.

[2] Z. Hamidi, C. Monstein, N. Shariff, Radio Observation of Coronal Mass Ejections (CMEs) Due to Flare Related Phenomenon on 7 th March 2012, (2012).

[3] Z.S. Hamidi, N.N.M. Shariff, F.N.Z. Ulum, Z.Z. Abidin, Z.A. Ibrahim, International Journal of Astronomy 5 (2012) 101-106.

[4] Z. Hamidi, N. Shariff, C. Monstein, Statistical Study of Nine Months Distribution of Solar Flares, (2014).

[5] N. Hashim, Z. Abidin, U. Ibrahim, R. Umar, M. Hassan, Z. Rosli, Z. Hamidi, Z. Ibrahim, Astronomical Society of the Pacific Conference Series 451 (2011) 4.

[6] Z. Hamidi, N. Shariff, C. Monstein, International Letters of Chemistry, Physics and Astronomy 13 (2014) 104-111.

[7] Z. Hamidi, N. Shariff, C. Monstein, Fundamental and Second Harmonic Bands of Solar Radio Burst Type II Caused by X1. 8-Class Solar Flares, (2014).

[8] Z. Hamidi, N. Shariff, C. Monstein, Scenario of Solar Radio Burst Type III During Solar Eclipse on 14 th November 2012, (2014).

[9] Z. Hamidi, N. Shariff, C. Monstein, International Letters of Chemistry, Physics and Astronomy 13 (2014) 144-154.

[10] Z. Hamidi, N. Shariff, C. Monstein, First Light Detection of A Single Solar Radio Burst Type III Due To Solar Flare Event, (2014).

[11] Z.S. Hamidi, N. Anim, N.N.M. Shariff, Z.Z. Abidin, Z.A. Ibrahim, C. Monstein, Dynamical structure of solar radio burst type III as evidence of energy of solar flares, in: R.Shukor (Ed.), PERFIK 2012, American Institute of Physics, Malaysia, 2013, pp. 11-15.

[12] N. Gopalswamy, et al., Sol. Phys. 259 (2009b) 227-254.

[13] Z. Hamidi, N. Shariff, C. Monstein, The Tendencies and Timeline of the Solar Burst Type II Fragmented, (2014).

[14] Z. Hamidi, N. Shariff, C. Monstein, W.W. Zulkifli, M. Ibrahim, N. Arifin, N. Amran, International Letters of Chemistry, Physics and Astronomy 9 (2014) 8-15.

[15] S. Maxwell, Thomas, Proc. I. R. E. 46 (1958) 142.

[16] S. Pohjolainen, Lehtinen N.J., $A \& A 449$ (2006).

[17] Nelson, a. Melrose, Solar Radiophysics Cambridge Univ. Press, New York, 1985.

[18] B. Vr`snak, Warmuth A., Temmer M., et al. , $A \& A 448$ (2006).

[19] M. Pick, Solar and Space Weather Radiophysics., in: D.E. Gary, C.U. Keller (Eds.), Dordrecht, 2004, pp. 17-45.

[20] M.R. Kundu, Radio observations of high energy solar flares, Highlights in Astronomy 12 (2002).

[21] M. Karlický, Kosugi T., $A \& A 419$ (2004). 
[22] Z. Hamidi, Z. Abidin, Z. Ibrahim, C. Monstein, N. Shariff, Signal Detection Performed by Log Periodic Dipole Antenna (LPDA) in Solar Monitoring, International Journal of Fundamental Physical Sciences (2012).

[23] G. Mann, Coronal Magnetic Energy Releases, Springer, Berlin, 1995.

[24] M.R. Kundu, Solar Radio Astronomy, John Wiley, 1965.

[25] V.V. Zheleznyakov, Radio Emission of the Sun and Planets (1970).

[26] A. Klassen, S. Pohjolainen, K.-L. \& Klein, Sol. Phys. 218 (2003).

[27] G.A. Dulk, W.C. Erickson, R. Manning, J.-L. Bougeret, $A \& A 365$ (2001) 294-300.

[28] G. Mann, A. Klassen, Astron. Astrophys. 441 (2005) 319-326.

[29] Z. Hamidi, U. Ibrahim, U.F. Salwa, Z. Abidin, Z. Ibrahim, N. Shariff, International Journal of Fundamental Physical Sciences 3 (2013).

[30] Z. Hamidi, Z. Abidin, Z. Ibrahim, C. Monstein, N. Shariff, M. Sabaghi, International Journal of Fundamental Physical Sciences 2 (2012).

[31] Z. Hamidi, N. Shariff, Z. Abidin, Z. Ibrahim, C. Monstein, E-Callisto Collaboration: Some Progress Solar Burst Studies Associated with Solar Flare Research Status in Malaysia, (2012).

[32] Z.S.Hamidi, Z. Abidin, Z. Ibrahim, N. Shariff, C. Monstein, Observations of coronal mass ejections (CMEs) at low frequency radio region on 15th April 2012, in: R.Shukor (Ed.), PERFIK 2012, American Institute of Physics, Malaysia, 2013, pp. 5.

[33] Z. Hamidi, N. Anim, N. Shariff, Z. Abidin, Z. Ibrahim, C. Monstein, Dynamical structure of solar radio burst type III as evidence of energy of solar flares, Persidangan Fizik Kebangsaan (PERFIK) 2012, Universiti Kebangsaan Malaysia, 2012, pp. 11-15.

[34] R.P. Lin, B.R. Dennis, G.J. Hurford, D.M. Smith, A. Zehnder, P.R. Harvey, et al., Sol. Phys. 210 (2002).

[35] Z. Hamidi, N. Shariff, The Propagation of An Impulsive Coronal Mass Ejections (CMEs) due to the High Solar Flares and Moreton Waves, (2014).

[36] Z. Hamidi, N. Shariff, M. Ali, C. Monstein, W.W. Zulkifli, M. Ibrahim, N. Arifin, N. Amran, International Letters of Chemistry, Physics and Astronomy 9 (2014) 84-92.

[37] Z. Hamidi, N. Shariff, C. Monstein, An Observation of an Inverted Type U Solar Burst Due to AR1429 Active Region, International Letters of Chemistry, Physics and Astronomy (2014).

[38] Z. Hamidi, N. Shariff, C. Monstein, Disturbances of Solar Eruption From Active Region AR1613, (2014).

[39] Z. Hamidi, N. Anim, N. Hakimi, N. Hamzan, A. Mokhtar, N. Syukri, S. Rohizat, I. Sukma, Z. Ibrahim, Z. Abidin, , International Journal of Fundamental Physical Sciences 2 (2012).

[40] Z. Hamidi, N. Shariff, C. Monstein, Z. Ibrahim, International Letters of Chemistry, Physics and Astronomy 7 (2014) 37-44.

[41] A.O. Benz, C. Monstein, H. Meyer, P.K. Manoharan, R. Ramesh, A. Altyntsev, A. Lara, J. Paez, K.-S. Cho, Earth Moon and Planets 104 (2009) 277-285. 
[42] Z.S.Hamidi, U.F.S.U. Ibrahim, Z.Z. Abidin, Z.A. Ibrahim, N.N.M.Shariff, International Journal of Fundamental Physical Sciences 3 (2013) 20-23.

[43] Z. Hamidi, Z. Ibrahim, Z. Abidin, M. Maulud, N. Radzin, N. Hamzan, N. Anim, N. Shariff, Designing and Constructing Log Periodic Dipole Antenna to Monitor Solar Radio Burst: e-Callisto Space Weather Project, (2011).

[44] Z.S. Hamidi, N. Shariff, Z. Abidin, Z. Ibrahim, C. Monstein, Middle-East Journal of Scientific Research 12 (2012) 6.

[45] Z.S.Hamidi, N.M.Anim, N. N.S.Hakimi, N.Hamzan, A.Mokhtar, N.Syukri, S.Rohizat, I.Sukma, Z.A. Ibrahim, Z.Z.Abidin, N.N.M.Shariff, C.Monstein, International Journal of Fundamental Physical Sciences 2 (2012) 4.

[46] R. Umar, Z.Z. Abidin, Z.A. Ibrahim, M.S.R. Hassan, Z. Rosli, Z.S. Hamidi, Population density effect on radio frequencies interference (RFI) in radio astronomy, AIP Conference Proceedings 1454 (2012) 39.

[47] Z. Hamidi, N. Shariff, C. Monstein, Evaluation of Spectral Overview and Radio Frequency Interference (RFI) Sources at Four Different Sites in CALLISTO Network at the Narrow Band Solar Monitoring Region, (2014).

[48] Z. Hamidi, N. Shariff, International Letters of Chemistry, Physics and Astronomy 5 (2014) 43-49.

[49] Z. Hamidi, Z. Abidin, Z. Ibrahim, N. Shariff, Indication of radio frequency interference (RFI) sources for solar burst monitoring in Malaysia, ICPAP 2011, AIP Conference Proceedings-American Institute of Physics 1454 (2012).

[50] N. Anim, Z. Hamidi, Z. Abidin, C. Monstein, N. Rohizat, Radio frequency interference affecting type III solar burst observations, 2012 NATIONAL PHYSICS

CONFERENCE:(PERFIK 2012), American Institute of Physics, 2013, pp. 82-86.

[51] R. Umar, Z. Abidin, Z. Ibrahim, N. Gasiprong, K. Asanok, S. Nammahachak, S. Aukkaravittayapun, P. Somboopon, A. Prasit, N. Prasert, Middle East Journal of Scientific Research 14 (2013).

[52] Z.S.Hamidi, N.N.M.Shariff, R.Umar, Malaysia Thailand Journal of Physics 3 (2012) 6.

[53] Z.S.Hamidi, Z. Abidin, Z. Ibrahim, C. Monstein, N. Shariff, Signal Detection Performed by Log Periodic Dipole Antenna (LPDA) in Solar Monitoring, International Journal of Fundamental Physical Sciences 2 (2012) 32-34.

[54] Z.S.Hamidi, N.N.M.Shariff, Evaluation of Signal to Noise Ratio (SNR) of Log Periodic Dipole Antenna (LPDA) Business Engineering and Industrial Applications Colloquium 2013, IEEE, Langkawi, Malaysia, 2013, pp. 434-438.

[55] R. Umar, Z. Abidin, Z. Ibrahim, N. Gasiprong, K. Asanok, S. Nammahachak, S. Aukkaravittayapun, P. Somboopon, A Prasit, N. Prasert, Z. Hamidi, N. Hashim, U.F.S.U. Ibrahim, Middle East Journal of Scientific Research 14 (2013) 861-866.

[56] Z. Hamidi, Z. Abidin, Z. Ibrahim, N. Shariff, C. Monstein, Modification and Performance of Log Periodic Dipole Antenna, International Journal of Engineering Research and Development 3 (2012) 36-39.

[57] Z.S.Hamidi, N.N.M. Shariff, International Journal of Science and Mathematics 2 (2014) 3. 
[58] Z.S.Hamidi, S. Chumiran, A. Mohamad, N. Shariff, Z. Ibrahim, N. Radzin, N. Hamzan, N. Anim, A. Alias, American Journal of Modern Physics 2 (2013) 4.

[59] Z.S.Hamidi, Z. Abidin, Z. Ibrahim, N. Shariff, Indication of radio frequency interference (RFI) sources for solar burst monitoring in Malaysia, ICPAP 2011, AIP Publisher, Indonesia, 2012, pp. 6.

[60] Z.S. Hamidi, N.N.M. Shariff, C. Monstein, The International Journal of Engineering 1 (2012) 3.

[61] C.K. C. Monstein, Bull. Astr. Soc. India 35 (2007).

[62] A.O. Benz, M. Guedel, H. Isliker, S. Miszkowicz, W. Stehling, Sol. Phys. 133 (1991) 385-393. 